\title{
Perancangan Bicycle Fork Menggunakan Pugh's Concept dan Software Elemen Hingga
}

\author{
Mohammad Kurniadi Rasyid ${ }^{1, a)}$, Dimas Prasetyo Aji ${ }^{2}$ \\ ${ }^{1}$ Program Studi Teknik Mesin ITI , ${ }^{2}$ Mahasiswa Program Studi Teknik Mesin ITI \\ Jl. Raya Puspiptek Serpong, Tangerang Selatan-Banten, Indonesia, 15320 \\ a) kurniadirasyid@iti.ac.id (corresponding author)
}

\begin{abstract}
Abstrak
Penelitian ini bertujuan membuat perancangan bicycle fork yang tepat untuk digunakan dalam pembuatannya. Model desain dianalisis melalui Pugh's concept dan perangkat lunak rekayasa Autodesk Inventor. Analisis difokuskan pada jenis bahan yang biasa digunakan untuk bicycle fork, yaitu Stainless steel 440C, Al 6061 dan Titanium. Pembebanan untuk setiap bicycle fork dibuat sama yaitu sebesar $700 \mathrm{~N}$ untuk arah tegak lurus penampang fork dan $350 \mathrm{~N}$ untuk arah paralel dengan penampang. Hasil penelitian menggunakan Pugh's concept menunjukkan total nilai untuk Stainless steel $440 \mathrm{C}$ paling baik yaitu 8.3 dibanding dengan total nilai untuk Alu 6061 sebesar 7.3 dan Titanium 6.8. Hasil analisis tegangan yang terjadi untuk material Al 6061, Stainless Steel 440C dan Titanium masing-masing: 546.1 MPa, 566.7 MPa dan 584.4 MPa. Dengan memperhatikan tegangan luluh maka yang aman digunakan untuk bicycle fork adalah Stainless Steel 440C dengan tegangan luluh $689 \mathrm{MPa}$. Besar deformasi untuk Stainless Steel 440C juga paling baik yakni $5.77 \mathrm{~mm}$ dibanding material Al $606117.35 \mathrm{~mm}$ dan Titanium $11.63 \mathrm{~mm}$.
\end{abstract}

Kata Kunci : elemen hingga, bicycle fork, Autodesk Inventor

\begin{abstract}
This study aims to choose the best material for bicycle forks especially those used on racing bicycles. The design model is analyzed through Pugh's concept and Autodesk Inventor engineering software. The analysis focused on the types of materials commonly used for bicycle forks, namely 440C Stainless steel, Al 6061 and Titanium. The loading for each bicycle fork is made equal to $700 \mathrm{~N}$ for the perpendicular cross section of the fork and $350 \mathrm{~N}$ for the parallel direction with the cross section. The results of the study using the Pugh's concept show that the total value for $440 \mathrm{C}$ Stainless steel is the best at 8.3 compared to the total value for Alu 6061 of 7.3and Titanium 6.8. The results of stress analysis that occurred for Al 6061, 440C Stainless Steel and Titanium materials respectively: 546,139 MPa, 566,706 MPa and 584,415 MPa. By paying attention to the yield stress, what is safe to use for bicycle forks is 440C Stainless Steel with a yield stress of $689 \mathrm{MPa}$. Deformation for 440C Stainless Steel is also the best at $5.77 \mathrm{~mm}$ compared to Al $606117.35 \mathrm{~mm}$ and Titanium $11.63 \mathrm{~mm}$.
\end{abstract}

Keyword : bicycle fork, finite element, Autodesk Inventor

\section{PENDAHULUAN}

Pada umumnya pembuatan untuk bicycle fork meggunakan material yang sama sebagaimana yang digunakan untuk rangka sepeda. Banyak pabrik pembuat sepeda khususnya sepeda balap kurang memperhatikan bahwa bicycle fork merupakan salah satu bagian terpenting dari sepeda karena bagian inilah yang mendapatkan tegangan paling besar. Penelitian ini dibuat adalah untuk mencari material yang paling baik untuk bicycle fork khususnya pada sepeda balap. Hingga saat ini penelitian tentang bicycle fork masih sedikit yang membuat dan meneliti. Tujuan penelitian ini untuk mencari desain bicycle fork dengan desain yang aman dan mempunyai ketahanan yang lebih baik dalam menahan beban. Laju sepeda sangat dipengaruhi oleh dua hal yaitu desain dan material. Pemilihan geometri yang terlalu besar akan mengakibatkan sepeda menjadi berat dan membuat lajunya menjadi lambat. Pemilihan material juga mempengaruhi laju sepeda. Material yang terlalu berat akan membuat laju lambat, sementara material yang terlalu ringan akan membuat sepeda mudah pengok atau patah saat tabrakan. Tanda panah pada Gambar 1 memperlihatkan posisi bicycle fork.

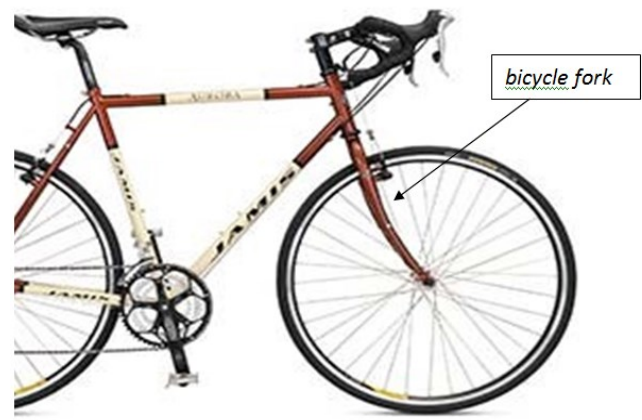

Gambar 1. Bicycle fork sepeda balap 


\section{TEORI DASAR}

Metode numerik menyediakan alat untuk menganalisis berbagai persoalan mekanika dengan geometri yang komplek. Diantara metode numerik yang banyak digunakan adalah metode elemen hingga. Metode ini mampu menghemat banyak waktu dan tenaga. Namun metode analisis ini membutuhkan banyak data untuk mendapatkan hasil dan konsumsi yang cukup akurat [1].

Metode elemen hingga pertama diperkenalkan oleh Richard Courant, 1943. Metode ini mendapatkan perkembangan yang cukup signifikan pada tahun 1956. Mulai tahun ini analisisnya meliputi sistem kekerasan dan defleksi dari material yang berbentuk kompleks. Cara kerja metode elemen hingga adalah dengan memecahkan elemen yang sangat komplek menjadi suatu elemen yang kecil. Saat ini metode elemen hingga telah diterapkan untuk menyelesaikan berbagai persoalan teknik, baik untuk menganalisis struktur, dinamika fluida, perpindahan panas, akustik, maupun elektromagnetik. Dalam proses perancangan atau pembuatan desain dari suatu produk penggunaan metode elemen hingga sering digunakan terutama dalam melakukan berbagai analisis kekuatan. Keunggulan dari metode ini adalah karena sangat efisien dan cukup akurat.

Proses ini diawali dengan pembuatan model geometri 3D yang kemudian ditransformasikan menjadi model elemen hingga yang terdiri dengan banyak elemenelemen node yang jauh lebih kecil. Proses perubahan ini meliputi perubahan dari model matematika menjadi model numerik. Keakuratan Metode Elemen Hingga sangat tergantung jumlah node. Semakin banyak elemen maka semakin akurat. Metode Elemen Hingga sangat sering digunakan untuk menganalisis tegangan dan kekuatan dari benda berikut kharakter yang terjadi akibat pembebanan. Metode Elemen Hingga dapat mempermudah menyelesaikan persoalan yang mungkin sulit untuk diselesaikan dengan perhitungan secara analitis. Metode ini terbukti telah memecahkan banyak kasus yang ada.

Salah satu cara mengetahui nilai tegangan maksimum yang terjadi pada suatu elemen benda adalah dengan cara menghitung penggabungan tegangan regangan dengan menggunakan formula tegangan Von Mises. Von Mises menyatakan bahwa akan terjadi luluh bilamana invarian kedua deviator tegangan melampaui harga kritis tertentu. Dengan kata lain luluh akan terjadi pada saat energi distorsi atau energi regangan geser dari material mencapai suatu nilai kritis tertentu. Secara sederhana dapat dikatakan bahwa energi distorsi adalah bagian dari energi regangan total per unit volume yang terlibat di dalam perubahan bentuk. Dalam ilmu material dan teknik, kriteria luluh Von Mises dapat juga diformulasikan dalam Von Mises stress atau equivalent tensile stress, $\sigma \mathrm{v}$, nilai tegangan scalar dapat dihitung dari tensor tegangan. Dalam kasus ini, material dikatakan mulai luluh ketika tegangan Von Mises mencapai nilai kritis yang diketahui sebagai yield strength.

\section{Penelitian Sebelumnya}

Jannetti dan Lynch [2] melakukan penelitian tentang fork sepeda yang berjudul "Fatigue Analysis of a Bicycle Fork". Penelitian ini menggunakan standar pengujian ASTM F2273-03 di dalam pengujiannya, dan untuk meneliti kelelahan yang terjadi digunakan analisis elemen hingga (FEA). Tujuan dari penelitian untuk menganalisis adanya kerusakan yang terjadi di bagian fork selama pengujian, dan melakukan optimasi terhadap fork tersebut. Setelah dilakukan simulasi, ditemukan adanya retak pada sambungan las antara steerer tube dan fork blades, atau disebut sebagai Heat Affected Zone (HAZ).

Penelitian berjudul "Fiber direction and stacking sequence design for bicycle frame made of carbon/epoxy composite laminate" oleh Chee Liu dan Chieh Wu dari Ming Chi University of Technology [3], menemukan adanya pengaruh kombinasi dari arah fiber di tiap ply dalam desain frame sepeda. Standar pengujian yang menjadi acuan dalam analisis ini adalah standar JIS D9401:1997, dan menggunakan analisis elemen hingga (FEA) dalam meneliti kegagalan yang terjadi. 33 kombinasi susunan ply ditentukan untuk mencari susunan yang terbaik. Frame sepeda terdiri dari beberapa tabung, dan tiap-tiap tabung terdiri dari 8 ply disusun secara simetri dengan arah yang berbeda di tiap ply dan tiap ply memiliki ketebalan $0.3 \mathrm{~mm}$.

Penelitian berjudul "Error estimation between simple, closed-form analytical formulae and full-scale FEM for interlaminar stress prediction in curved laminates" oleh Most, Stegmair dan Petry dari Airbus Helicopters-Jerman [4] menganalisis atau mengamati perbedaan hasil perhitungan interlaminar stress pada struktur secara analisis dan finite element. Penelitian tersebut memperlihatkan hasil perhitungan manual pada struktur dan juga perhitungan secara finite element dilakukan dengan menggunakan perangkat lunak Nastran dengan memilih dua jenis pengaturan simulasi yang berbeda, yaitu solid element dan shell element. Pengujian memperlihatkan pengaruh beban momen, torsional dan longitudinal; pada struktur setelah diberikan beban bending; dan beban pressure.

\section{METODE PENELITIAN}

\section{Disain Penelitian}

Gambar 2 menunjukkan tahapan desain yang digunakan untuk melakukan simulasi numerik terhadap bicycle forks. Ide dan konsep yang dihasilkan kemudian dipilih dengan menggunakan metode pemilihan matriks keputusan Pugh [5] dan [6] . Tiga konsep desain dibuat. Computer Aided Design (CAD) perangkat lunak digunakan dalam merancang model-model dari bicycle forks. Selanjutnya model-model CAD yang sudah dibuat dianalisis melalui perangkat lunak rekayasa Autodesk Inventor. Analisis elemen hingga dilakukan oleh perangkat lunak ini terhadap model-model tadi. Analisis difokuskan pada jenis bahan yang biasa digunakan untuk 
bicycle forks, yaitu steel 440C, Al 606i dan Titanium. Lendutan dan tegangan yang terjadi kemudian dievaluasi.

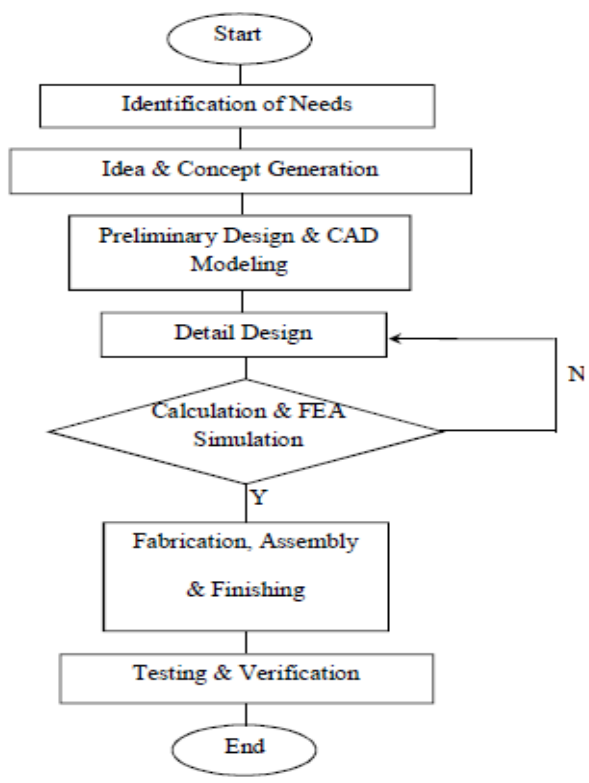

Gambar 2. Desain penelitian

Gambar 3 menunjukkan ukuran dari bicycle forks yang akan dirancang.

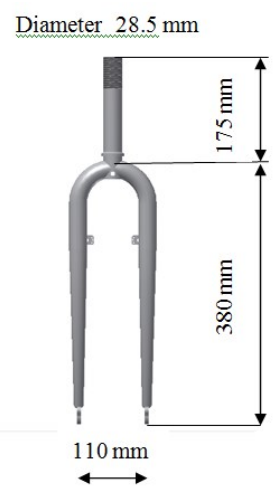

Gambar 3. Dimensi bicycle fork

Karakteristik material yang digunakan ditunjukkan pada tabel 1. Pengurangan berat pada material steel dapat mengurangi bahaya keretakan [7].

Tabel 1. Mechanical properties

\begin{tabular}{llll}
\hline & $\begin{array}{l}\text { Aluminum } \\
6061\end{array}$ & $\begin{array}{l}\text { Stainless Steel, } \\
440 \mathrm{C}\end{array}$ & Titanium \\
\hline $\begin{array}{l}\text { Mass Density } \\
\text { Yield Strength }\end{array}$ & $\begin{array}{l}2.71 \mathrm{~g} / \mathrm{cm}^{3} \\
275 \mathrm{Mpa}\end{array}$ & $\begin{array}{l}7.75 \mathrm{~g} / \mathrm{cm}^{3} \\
689 \mathrm{MPa}\end{array}$ & $\begin{array}{l}4.51 \mathrm{~g} / \mathrm{cm}^{3} \\
275.6 \mathrm{MPa}\end{array}$ \\
$\begin{array}{l}\text { Ultimate } \\
\text { Tensile }\end{array}$ & $310 \mathrm{Mpa}$ & $861.25 \mathrm{MPa}$ & $344.5 \mathrm{MPa}$ \\
$\begin{array}{l}\text { Strength } \\
\text { Young's }\end{array}$ & & & \\
$\begin{array}{l}\text { Modulus } \\
\text { Poisson's Ratio }\end{array}$ & $0.33 \mathrm{ul}$ & $206.7 \mathrm{GPa}$ & $102.81 \mathrm{GPa}$ \\
Shear Modulus & $25.9023 \mathrm{Gpa}$ & $0.27 \mathrm{ul}$ & $0.361 \mathrm{ul}$ \\
\hline
\end{tabular}

Pembebanan material diberikan pada penyangga bicycle fork dengan besar gaya $700 \mathrm{~N}$ pada bagian atas searah sumbu $\mathrm{Y}$ dan $350 \mathrm{~N}$ pada arah sumbu $\mathrm{Z}$ seperti diperlihatkan oleh kedua tanda panah pada gambar 4.

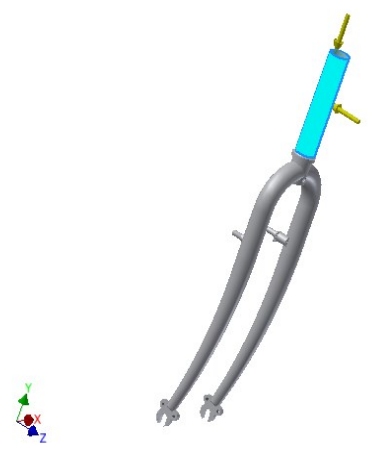

Gambar 4. Posisi pembebanan

Posisi penahan dari penyangga ada pada pada posisi samping seperti terlihat pada gambar 5 .

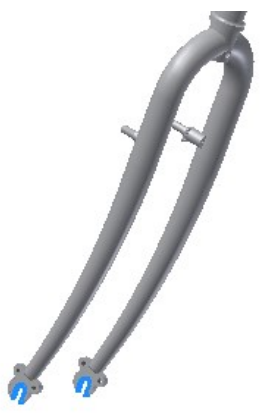

Gambar 5. Posisi penahan (constraint)

\section{HASIL DAN PEMBAHASAN}

Hasil analisis terdiri dari analisis tegangan dan analisis yang terjadi pada model 3D CAD yang telah didisain, diperoleh melalui simulasi FEA menggunakan software.

\section{Analisis Kekuatan/Tegangan}

Secara keseluruhan hasil perhitungan tegangan von Mises ditunjukkan pada tabel 2.

Tabel 2. Hasil analisis software

\begin{tabular}{llll}
\hline Name & Al 6061 & $\begin{array}{l}\text { Stainless } \\
\text { Steel, } \\
\text { 440C }\end{array}$ & Titanium \\
\hline Von Mises Stress & $437.5 \mathrm{MPa}$ & $461.0 \mathrm{MPa}$ & $436.5 \mathrm{MPa}$ \\
1st Principal Stress & $546.1 \mathrm{MPa}$ & $566.7 \mathrm{MPa}$ & $584.4 \mathrm{MPa}$ \\
3rd Principal Stress & $155.7 \mathrm{MPa}$ & $110.5 \mathrm{MPa}$ & $170.0 \mathrm{MPa}$ \\
Displacement & $17.4 \mathrm{~mm}$ & $5.8 \mathrm{~mm}$ & $11.6 \mathrm{~mm}$ \\
Safety Factor & $0.63 \mathrm{ul}$ & $1.5 \mathrm{ul}$ & $0.63 \mathrm{ul}$ \\
\hline
\end{tabular}

Dari tabel 2 dapat diketahui hasil tegangan yang terjadi untuk material Al 6061, Steinless Steel 440C dan Titanium yang terbesar adalah tegangan tekan dengan besar masing-masing sebagai berikut: $546.1 \mathrm{MPa}, 566.7$ 
MPa dan 584.4 MPa. Distribusi tegangan yang terjadi ditunjukkan pada gambar 6 .

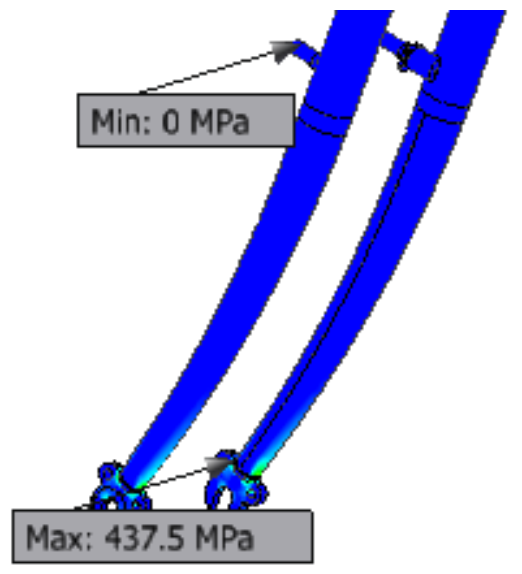

Gambar 6. TeganganVon Mises yang terjadi

Tegangan Von Mises paling besar berada pada daerah yang ditunjuk oleh anak panah yaitu pada daerah ujung batang yang paling kecil, sementara tegangan terendah pada daerah warna biru yang terletak disekitar tengah.

\section{Analisis Lendutan}

Sementara deformasi yang terjadi bisa dilihat pada gambar 7 .

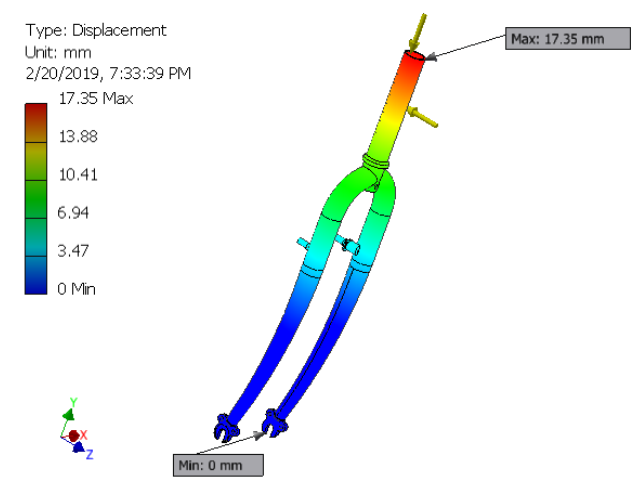

Gambar 7 . Analisis lendutan

Pada gambar 7 terlihat daerah yang paling besar mengalami deformasi ada dibagian yang berwarna merah dengan arah sumbu Z. Hal ini wajar karena disini bekerja pembebanan maksimal. Besar deformasi untuk ketiga material: Al $606117.4 \mathrm{~mm}$, Stainless Steel 440C 5.8 $\mathrm{mm}$, dan Titanium $11.6 \mathrm{~mm}$.

\section{Analisis Nilai/Faktor Keamanan}

Analisis nilai keamanan dapat dilihat pada gambar 8 untuk ketiga material. Sementara itu daerah yang perlu diberikan perhatian ada pada daerah yang tingkat safety paling kecil seperti terlihat pada gambar.

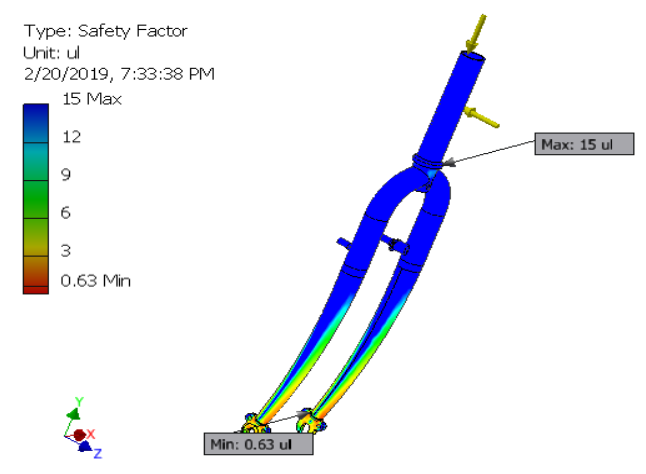

Gambar 8 . Daerah kritis

Pada gambar 8 terlihat daerah yang perlu diberikan perhatian ada pada daerah bawah karena nilainya paling kecil dari tingkat amannya. Nilai aman terkecil untuk setiap material Al 6061, Stainless Steel 440C, dan Titanium berturut-turut $0.63,1.5$ dan 0.63 .

\section{Analisis Berat}

Hasil analisis terhadap berat rangka menunjukkan Al 6061 mempunyai berat yang paling ringan dengan massa jenis $2.71 \mathrm{~g} / \mathrm{cm}^{3}$ dan stainless steel paling berat 7.75 $\mathrm{g} / \mathrm{cm}^{3}$ diikuti Titanium $4.51 \mathrm{~g} / \mathrm{cm}^{3}$ sedangkan volume ketiga model sama.

\section{Analisis Biaya}

Analisis biaya ditentukan berdasarkan harga material di lapangan. Harga untuk satu kilogram batang round bar di website Alibaba.com untuk Stainless steel paling murah yakni US\$2, diikuti Alu 6061 US\$5.3, dan Titanium US\$14.5.

\section{Analisis Pugh's Concept}

Analisis keputusan menggunakan Pugh's concept ditunjukkan pada tabel 3 .

Tabel 3. Pugh decision matrix design selection.

\begin{tabular}{llll}
\hline $\begin{array}{l}\text { Kriteria } \\
\text { Penilaian }\end{array}$ & $\begin{array}{l}\text { Material 1 } \\
\text { (Stainless } \\
\text { steel) }\end{array}$ & $\begin{array}{l}\text { Material 2 } \\
\text { (Alu 6061) }\end{array}$ & $\begin{array}{l}\text { Material 3 } \\
\text { (Titanium) }\end{array}$ \\
\hline Kekuatan & 9 & 7 & 7 \\
Kekakuan & 7 & 3 & 5 \\
Biaya & 9 & 8 & 6 \\
Keamanan & 10 & 8 & 8 \\
Berat & 6 & 9 & 8 \\
Ketersediaan & 9 & 9 & 7 \\
Total & $\mathbf{8 . 3}$ & $\mathbf{7 . 3}$ & $\mathbf{6 . 8}$ \\
\hline
\end{tabular}

Hasil analisis menggunakan Pugh's concept pada Tabel 3 menunjukkan total nilai untuk Stainless steel paling besar yaitu 8.3 dibanding dengan total nilai untuk Alu 6061 sebesar 7.3 dan Titanium 6.8.

\section{V.KESIMPULAN}

1. Hasil tegangan yang terjadi untuk bicycle fork dengan material Al 6061, Stainless Steel 440C, dan Titanium yang terbesar adalah tegangan tekan 
dengan besar masing-masing sebagai berikut: 546.1 $\mathrm{MPa}, 566.7 \mathrm{Mpa}$, dan 584.4 MPa.

2. Berdasar pengujian yang menyatakan tegangan luluh Al $6061275 \mathrm{MPa}$, Stainless Steel 440C 689 $\mathrm{MPa}$, dan Titanium 275.6 MPa, maka yang aman digunakan untuk bicycle fork adalah Stainless Steel 440C.

3. Hasil analisis menunjukkan bahwa safety factor minimal untuk Al 6061 dan Titanium masih dibawah 1 sehingga dimensi struktur sebaiknya diubah hingga safety factor berada antara 1 sampai 10, sementara nilai safety factor terkecil untuk Stainless Steel 440C sebesar 1.5, sehingga material ini masih dapat digunakan untuk bicycle fork.

4. Besar deformasi untuk ketiga material: Al 6061 $17.35 \mathrm{~mm}$, Stainless Steel 440C $5.77 \mathrm{~mm}$, dan Titanium $11.63 \mathrm{~mm}$.

5. Dilihat dari kekuatan menahan beban dan deformasi yang terjadi maka hanya Stainless Stell $440 \mathrm{C}$ yang masih dapat digunakan untuk material bicycle fork.

6. Hasil analisis Pugh' concept menunjukkan disain dengan material stainless steel mendapatkan nilai paling tinggi yakni 8.3 sehingga paling dianjurkan untuk dipilih.

\section{UCAPAN TERIMA KASIH}

Kami ingin mengucapkan terimakasih yang sebesarbesarnya terhadap semua pihak yang telah membantu khususnya Institut Teknologi Indonesia baik dari jurusan Mesin ITI juga LP3M-ITI.

\section{REFERENSI}

[1] H. Andruet, Special 2-D and 3-D Geometrically nonlinear finite elements for analysis of adhesively bonded joints, Unpublished Doctoral Dissertation, Virginia Polytechnic Institute, USA, 1998.

[2] Jannetti, N.A., Lynch, L.B., Fatigue Analysis of a Bicycle Fork. Worcester: Worcester Polytechnic Institute.

[3] Chee Liu T. dan Chieh Wub H., Fiber direction and stacking sequence design for bicycle frame made of carbon/epoxy composite laminate. Materials \& Design. 31, 4: 1971-1980. 2009.

[4] Most J., Stegmair D. dan Petry D., Error estimation between simple, closed-form analytical formulae and full-scale FEM for interlaminar stress prediction in curved laminates. Composite Structure. 131:72-81. 2015.

[5] Thakker, A., Jarvis, J., Buggy, M. and Sahed, A. 3D$\mathrm{CAD}$ conceptual design of the next-generation impulse turbine using the Pugh decision-matrix. Materials \& Design, 30(7): 2676-2684. 2009.

[6] Ulrich, K.T. and Eppinger, S.D. 2008. Product design and development. $4^{\text {th }}$ Edition. New York: McGraw-Hill.

[7] Pushpendra Kumar Sharma and Borse Rajendra R., Fatigue analysis and optimization of connecting rod using finite element analysis. International Journal of advance research in Science and Engineering 1(1): 336337. 2012.
[8] Mingzhou, S., Qiang, G. and Bing, G., Finite element analysis of steel members under cyclic loading. Finite Elements in Analysis and Design, 39 (1): 43-54. 2002. 